\title{
Fictitious Spokesperson to Enhance Corporate Environmental Image
}

\author{
Xiuqiang Pan and Yu-Ming Fei
}

\begin{abstract}
In recent years the fictitious spokesperson have been widely adapted by enterprises as one of their new marketing methods that not only serves as company icon but also affects consumer's behaviour in different aspects. The research analyzed how the fictitious character which created by the enterprise has the influence on the customer behavior in environmental aspect. This research used the President Chain Store Corp., and its fictitious character- Open-Jiang as an example and proceeded the SEM analysis by analyzing a questionnaire survey which comprise five aspects such as the Open-Jiang environmental image, spokesman acceptance, corporate image, product accepts and loyalty share. As the verification of the research model showed, the Open-Jiang environmental image has a positive influence on loyalty share. When the consumer had higher sympathy with the fictitious character, there is a high acceptance of environmental concept which delivered by the enterprise through the fictitious character.
\end{abstract}

Index Terms-Fictitious spokesman, environmental image, loyalty.

\section{INTRODUCTION}

The competition among convenience stores which under different leading brands has become fierce today. Enterprises would make every effort to consolidate their existing market share, stimulate customer's consumption to increase sell. However, the similarity of products and services which different convenience store supply has made it a laborious task for all enterprises. The fictitious personages, normally with the cute cheerful cartoon look, now have become enterprises' favorite not only to distinguish their stores from others' but also create varied additional value.

It is not new that fictitious personages have been used in all kinds of commercial and make a strong image between fictitious personages and products they represent, for example Michelin Tires and its striking white fat doll. With progressing animation technology, fictitious personages nowadays can interact with customers through many thrilling ways. For example, inter-dynamic of network situation, advertisement, exclusive song, life experience background, consumers start to have great empathy with thoese little fictitious personages. Utilize the marketing result of the fictitious personages of the leading factors in order to create enterprise's difference. Sirgy [1] points out in products of the highest personification. The relation that the self- concept keeps the same with images of the products among choosing

Manuscript received February 5, 2013; revised March 28, 2013.

The authors are with the Department of Information and Communication, Zhejiang Industry \& Trade Vocational College, China (e-mail: xiuqiang.pan@qq.com, fander@cute.edu.tw). with consumers is forward. And consumers will usually choose use and one's own individual and similar brand. The customer expects to use the brand with similar individual character. If brand characteristic can be produced in a personalized way, will set up customer's emotion links. Consumers will have a more positive attitude that supports on brand. So, can let the corporate image melt, and let consumers approve vivaciously with fictitious personages, enterprises can use, on sale throughout resource in products fictitious personage.

Aaker and Keller [2] think a successful brand should possess and extend the tactics. Except adopt the position in the mind of consumer of the original brand. Must continue maintaining customers to brand loyalty. Moreover original brand and extend between the product can produce "Reciprocal Effecting". Make use of fictitious personage to set up corporate image and create brands. Let consumers participate in the inter-dynamic of the fictitious personages in order to produce loyalty. As speak on behalf every product that enterprises promote with fictitious personage. Though consumers lack knowledge of the extension products of enterprises. But fictitious personages will influence the appraisal that the products extended directly. Muthukrishnan and Weitz [3] think consumers' subjective product knowledge will influence their cognition to agreeing with a degree. When consumer's knowledge of the products is scarce, the consciousness risk but will be improved. So will relatively rely on the famous brand [4]. Therefor subjective knowledge of consumer change can fictitious personage in brand produce acceptance. The products to enterprises may accept degree is relatively big, therefore relatively have market share.

If enterprises should meet the environment of the market competition, Webster [5] regards customer as the starting point, is regarded as the most important resources of the enterprise the customer to point out primarily, and should regard long-term relation kept the tactics with customer as and that is to set up customer loyalty. Will establish good long-term relation with the customer, among them the most important work is to improve the customer's image to enterprises. It is to achieve the goal of continuing management to create customers satisfied on the highly competitive market forever in enterprises. It will be the initial approach to become a Buddhist believer that enterprises succeed to improve customers satisfied. [6]-[9]

Touch upon the loyalty to the brand or service, mostly regard buying the indicator repeatedly or purchasing the wheel again as. Heskett, et al. [10] research points out ' loyalty ' (Loyalty) Consumers are too faithful to turn into the intensity to some particular enterprises, shops or brands. 
Dick and Basu [11] think that only canvasses the behavioral aspect theory simply and cannot totally explain customer's loyalty; the research of customer loyalty must still be put into the doing in the test amount factor of the psychological aspect Oliver, Rust and Varki [12] research points out customer's loyalty means when the customer is influenced by environment and on sale throughout the tactics, purchase again behavior still to commodities or services that fond of. The customer will change the taste in the product. The reason is that the customers, to the owner satisfaction with the firm base of the deep roots of the brand, are not influenced by external possible moving and buys the behavioral factor more. Have scholar too from different to discuss in terms of loyalty. Wangenheim [13] divide loyalty into active loyalty and passive loyalty. Skogland [14] also divide customer's loyalty into attitudinal loyalty and word of mouth loyalty. Therefore when this research designs the loyalty questionnaire, in order to share voluntarily and positive attitude.

One aspect in particular of this matter seems worth mentioning. Today, the business council for sustainable development and environmental protection are closely integrated. Because of more popular environmentalism in the world, the sales of green products is growing acceptance. Neal and Strauss [15] said "Creating a strong brand in the market is one of their main goals because it can provide benefits for them." Therefore, the value of brand equity, none explored them about green or environmental issues. In this study wanted to fill the research gap. Green brand image could creat by fictitious spokesperson.

The 7-11 enterprise, in order to transmit keeping watch and helping defend each other with friendly and cordial meaning, has created Open-Jiang (see Fig. 1). The 7-11, with one layer of link of the goods, target guest appropriately. Open-Jiang has over 100 multi-type consumption nature products and interesting collections at present. This has further strengthened the difference between it and competitor too. The 7-11 takes the lead until the regard fictitious personage as and combine marketing, spreads and creates the comprehensive result. It is ripe to grow up with OPEN-Jian gradually, customer foundation group is wider and wider. Open-Jiang, for wanting the angle of marketing of convenience stores. So, this research will canvass Open-Jiang to mould the factor to the 7-11 corporate images.

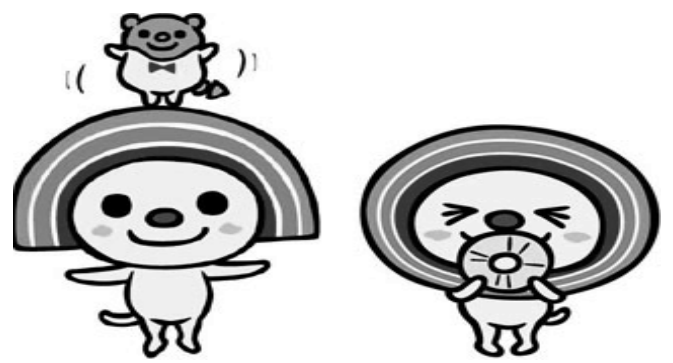

Fig. 1. The 7-11 OPEN-Jiang created. (The figure from the Open-Jiang's wizarding word.[16])

\section{RESEARCH INSTRUMENTS}

The study collected research information regarding participation in the 7-11's product launch. The product launch will be held in the province of Taiwan. The measurement of the questionnaire items was by use of "five-point Likert scale from 1 to 5 " rating for "strongly disagree" to "strongly agree." The scale designed for the study consisted of five constructs: "Spokesman acceptance," "Product accepts," "Corporate image," "Open-Jiang environmental image," and "Loyalty share." This study applied the questionnaire survey to verify the hypotheses and research framework. The study referred to previous studies to design questionnaire items. The questionnaire is described in Mandarin, before mailing to the respondents, five experts and scholars were asked to modify the questionnaire in the first pretest. Then the questionnaires were randomly mailed to 30 consumers who had the experience participating 7-11's regular commercial promotions and they were asked to fill in the questionnaire. 22 items in the questionnarire were left valid after consistency reliability test, therefore, the questionnaire of this study had a high level of content validity.

The construct of Open-Jiang environmental image primarily assessed customer's acquaintance with Open-Jiang's healthy-diet and nature-loved life style. The construct of spokesman acceptance primarily assessed Open-Jiang's adorable appearance and pleaseant personality it represented. The construct of Corporate image primarily assessed the image of a kind of consciousness of enterprises to the outside. The construct of the product accepts primarily assessed the customer accepts the intensity about the product demand. The construct of loyalty share primarily assessed customer's will with sharing voluntarily of fondness to the products.

\section{A. Research Participants}

Questionnaires were collected from different counties of Taiwan. From September 2011 to June 2012, following was introduced Open-Jiang and his fictitious family members to the public in 7-11's regular commercial promotions, 1322 questionnaires were distributed and 867 questionnaires were returned (a 66\% response rate). After incomplete questionnaires were eliminated, data were obtained from 785 questionnaires, and the effective response rate was 59\%.

The sample included more male than female participants; 367 participants were male (46.8\%) and $418(53.2 \%)$ were female. With regard to participating jobs, 285 were university students $(36.4 \%)$ and 499 were on-the-job workers $(63.6 \%)$. Accounts for $37 \%$ under amount of money $10 \mathrm{RMB}$ of consumption of buying the products 7-11 person every day. The person who consumes 11-20 RMB accounts for $36 \%$.

\section{RESEARCH RESULTS}

Based on the research evidence, we used SPSS 19 and LISREL 8.8 software to perform reliability analysis, factor analysis, structural equation modeling (SEM), and other research tests on the data from valid questionnaires. SEM was used to explore the causal relationship between variables and to examine the relationships among different hypothetical models to verify our theoretical framework. SEM of this study examined the two levels of analysis, the measurement model and structure model, and their results are shown here below. 


\section{A. Item Analysis with Composite Reliability and Convergent Validity}

The study used SPSS 19 as an analytical tool to carry out descriptive statistics, factor loading, and t-value calculations in order to understand the items of the study. Internal consistency can be determined by examination of the composite reliability (CR) of the constructs [17], and all CR values in the present study ranged from .72 to .89 , surpassing the suggested threshold value of 0.7 [18], [19]. The results of the measurement model validation was discussed extensively in the literature, but most authors merely offer terminology instead of a methodology [20]. Convergent validity referred to the degree to which multiple items measure one constructs. Convergent validity in the present study was evaluated by checking whether (1) the average variance extracted (AVE) values were larger than 0.5 [17] and (2) the factor loadings of all items were significant and higher than 0.5 [18]. All these conditions were met, indicating the acceptable convergent validity. Additionally, all t-values were significant, showing that all items were discriminative, and all items were able to identify the degree of response for different samples. (See Table 1)

TABLE I: FACTOR AND RELIABILITY ANALYSIS

\begin{tabular}{|c|c|c|c|c|}
\hline Dimension & $\begin{array}{c}\text { Number of } \\
\text { questionnaire items }\end{array}$ & MeanSD & $\begin{array}{c}\text { Cronbach's } \\
a\end{array}$ & CR \\
\hline Open-Jiang & 4 & 3.41 .86 & .83 & .79 \\
\hline environmental image & 4 & 3.94 .82 & .92 & .89 \\
\hline Spokesman acceptance & 4 & 3.34 .94 & .85 & .82 \\
\hline Corporate image & 5 & 3.87 .92 & .88 & .72 \\
\hline $\begin{array}{l}\text { Product accepts } \\
\text { Loyalty share }\end{array}$ & 5 & 3.85 .88 & .90 & .86 \\
\hline
\end{tabular}

TABLE II: THE CORRELATION MATRIX

\begin{tabular}{lcc}
\hline & $\begin{array}{c}\text { Open-Jiang } \\
\text { environmental image }\end{array}$ & $\begin{array}{l}\text { Spokesman } \\
\text { acceptance }\end{array}$ \\
\hline Corporate image & $.72^{* *}$ & $.68^{* *}$ \\
Product accepts & $.61^{* *}$ & $.63^{* *}$ \\
Loyalty share & $.66^{* *}$ & $.57^{* *}$ \\
\hline
\end{tabular}

The construct validity of the research instruments was established using confirmatory factor analysis. All factor loadings were statistically significant and ranged from .63 to .85 . To evaluate the consistency of the variables, reliability analysis of the questionnaire was identified using Cronbach's $\alpha$. According to Nunnally [18], a Cronbach's $\alpha$ value above 0.5 indicated an acceptable level of reliability. Table 1 showed Cronbach's $\alpha$ values and indicated that all values were above 0.5 and that the reliability coefficient for the entire questionnaire was .939, which suggests that the variables were reliable. Table 1 showed that the mean values of each dimension were between 3.41 and 3.94 and that the standard deviations were small, indicating a low degree of dispersion.

Table II showed that there was a significant positive correlation between most of the various dimensions. All of factors did have significant correlation. There are positive correlations among Open-Jiang environmental image, corporate image, product accepts and loyalty share.

\section{B. Model Goodness of Fit Test}

This study used SEM with LISREL to test the goodness of fit for the model. The results of the structure model was hypothesized as $x^{2}=591.75, \mathrm{df}=202$, with a probability level $p=0.00, R M S E A=0.053, G F I=0.93$, and $A G F I=0.89$, in which $G F I$ and $A G F I$ were higher than 0.8 and $R M S E A$ was lower than 0.08 , representing that this model fit the data best.

TABLE III: THE RESULTS OF THE STRUCTURAL MODEL

\begin{tabular}{llll}
\hline Hypothesis & Proposed effect & Path Coefficient & Results \\
\hline $\mathrm{H}_{1}$ & + & $.78^{* *}$ & $\mathrm{H}_{1}$ is supported \\
$\mathrm{H}_{2}$ & + & $.84^{* *}$ & $\mathrm{H}_{2}$ is supported \\
$\mathrm{H}_{3}$ & + & $.13^{*}$ & $\mathrm{H}_{3}$ is supported \\
$\mathrm{H}_{4}$ & - & -.01 & $\mathrm{H}_{4}$ is not supported \\
$\mathrm{H}_{5}$ & + & $.50^{* *}$ & $\mathrm{H}_{5}$ is supported \\
$\mathrm{H}_{6}$ & + & $.48^{* *}$ & $\mathrm{H}_{6}$ is supported \\
\hline
\end{tabular}

${ }^{*} \mathrm{p}<0.05, * * \mathrm{p}<0.001$

Hair et al. [19] proposed that researchers should consider the Chi-square values and other measures of fitness concurrently. The overall fit measures of the SEM in this study indicate that the fit of the model is very good. The values of fitness were all larger than $0.9(N F I=0.98, R F I=$ $0.97, I F I=0.98, T L I=0.98$, and $C F I=0.98)$. Overall, the comprehensive indicators show that the theoretical model fits the overall pattern of the data.

The results of the full model in this study are shown in Table 3. Apart from spokesman acceptance to product accepts that the path was not significant, all other paths estimated are significant, and hypotheses are supported in this study. Fig. 2 shows the path analysis affect customer loyalty share. The study suggest the following tentative conclusions: (1) Open-Jiang environmental image is an important factor affecting loyalty share. (2) This study also verified corporate image and product accepts had partial mediation effects on the positive relationship between open-jiang environmental image and loyalty share.

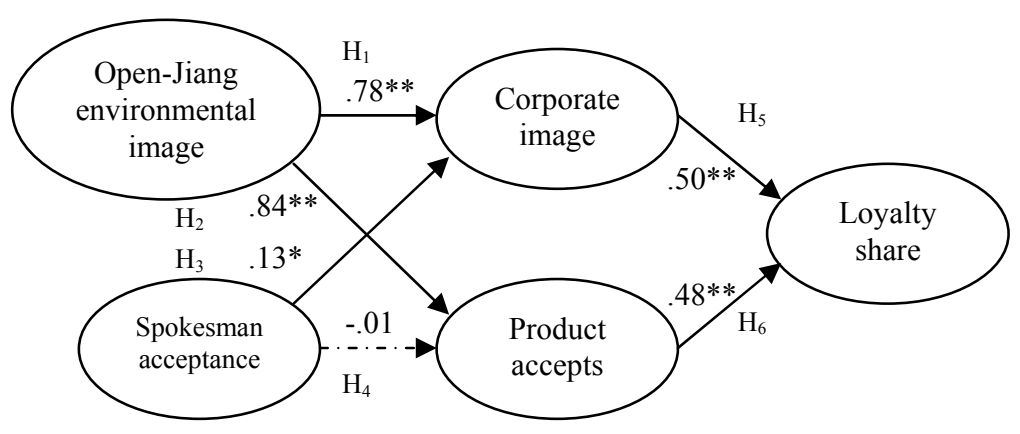

Fig. 2. Verification of the research model 


\section{CONCLUSION AND SUGGESTION}

Because consumer's loyalty issues have become a mainstream in the area of managerment, and consumers had increased more environmentsl friendly. Therefore, environmental image is one of the inevitable trends for companies, and its concept has been widely accepted had applied in recent years.

Although prior researches widely discussed about fictitious spokesperson issues, there has been no study exploring the concept of environmental image in the branding literature. In order to fill this research gap, this article proposed two novel constructs - fictitious spokesperson and it's environmental image - and developed a research framework to further discuss their relationships. In addition, the positive relationship between Open-Jiang environmental image and loyalty share is partially mediated by corporate image and product accepts. Most of the hypotheses proposed in this article are supported in this study. Therefore, this study suggests that companies should invest more resources in upgrading design of fictitious spokesperson. Let fictitious spokesperson arouse popular concerns about environmental issues, introduce environmental-friendly products, attract potential consumers to further expand markets.

This study was undertaken in the case of information and the 7-11 business in Taiwan, so that curther studies can focus on other business in other countries and compare with this study. This result of the study finds that consumer has higher acceptance of the environmental image which enterprise delivered through fictitious personages. Consumer's loyalties also strongly developed simultaneously. The Open-Jiang environmental image is the most important factor influencing customer loyalty. Therefore, it is a low-cost but high-effort method to increase sales amout when fictitious personage is integrated into commercial promotion as environmental concepts have gained more and more attention these days.

Holbrook [20] point out customer's value is that one kind is inter-dynamic, relative, is fond of the experience. The structural equation modeling can understand consumers have forward effects on acceptance and consumption loyalty of Open Jiang pathbreaker's acceptance andconsumern loyalty of 7-11 of this research. If enterprises should keep customers here and increase their repeated purchase. It should change customer satisfaction into customer's value and customer loyalty. Briefly, the use of virtual spokesperson is consistent with the concept of environmental protection, it can save a lot resources and decline the waste. Finally, this author hopes that the research results are helpful to managers, researchers, practitioners, and governments, and provide useful contribution to relevant studies and future researches as reference.

\section{REFERENCES}

[1] J. Sirgy, "Self-concept in consumer behavior: a critical review," Journal of Consumer Research, vol. 9, pp. 287-300, December 1982.
[2] D. A. Aaker, "Brand exten sinons:the good, the bad, and ugly," Sloan Management Review, vol. 31, pp. 47-56, 1990.

[3] A. V. Muthukrishnan and B. A. Weitz, "Role of product knowledge in evaluation of brand extension," Advances in Consumer Research, vol. 18, pp. 407-413, May 1991.

[4] D. C. Smith and C. W. Park, "The effects of brand extension on market share and advertising efficiency," Journal of Marketing Research, vol. 29, pp. 296-313, August 1992.

[5] F. E. Jr. Webster, "Defining the new marketing concept," Marketing Management, vol. 2, no. 4, pp. 22-31, 1994.

[6] J. A. Howard and J. N. Sheth, The Theory of Buyer Behavior, John Wiley and Scons Inc., New York, NY, 1969.

[7] G. A. Churchill and C. Surprenant, "An investigation into the determinants of customer satisfaction," Journal of Marketing Research, vol. 19 , No. 4, pp.491-504, 1982.

[8] A. Ostrom and D. Iacobucci, "Consumer Trade-Offs and the Evaluation of Services," Journal of Marketing, vol. 59, no. 1, pp.17-28, 1995.

[9] W. Fonvielle, "How to know what customers really want," Training and Development, vol. 51, no. 9, pp.40-44, 1997.

[10] J. L. Heskett, T. O. Jones, G. W. Loveman, W. E. Sassed Jr., and L. A. Schlesinger, "Putting the service profit chain to work," Harvard Business Review, vol. 72, pp. 164-174, 1994.

[11] A. S. Dick and K. Basu, "Customer loyalty: Toward an integrated conceptual framework," Journal of the Academy of Marketing Science, vol. 22, pp. 99-113, 1994.

[12] R. L. Oliver, R. T. Rust, and S. Varki, "Customer delight: Foundations, findings and managerial insight," Journal of Retailing, vol. 73, pp. 311-336, 1997.

[13] V. F. Wangenheim, "Situational characteristics as moderators of the satisfaction-loyalty link: An investigation in a business-to-business context," Journal of Consumer Satisfaction, Dissatisfaction and Complaining Behavior, vol. 16, pp.145-156, 2003.

[14] I. Skogland and A. J. Siguaw, "Are your satisfied customers loyal," Cornell Hotel and Restaurant Administration Quarterly, vol. 45, pp. 221-234, 2004.

[15] W. Neal and R. Strauss, "A Framework for Measuring and Managing Brand Equity," Marketing Research, vol. 20, no. 2, pp. 6-12, 2008.

[16] 7-Eleven Design. (2011). The Open-Jiang's Wizarding World. President Chain Store Corporation. [Online]. Available: http://www.openopen.com.tw/profile/index.asp.

[17] C. R. Fornell and F. F. Larcker, "Structural equation models with unobservable variables and measurement error," Journal of Marketing Research, vol. 18, pp.39-51, 1981.

[18] J. C. Nunnally, Psychometric Theory, New York: Mc Graw-Hill, 1978.

[19] J. F. Hair, R. E. Anderson, R. L. Tatham, and W. C. Black, Multivariate Data Analysis (5th ed), Upper Saddle River, NJ: Practice Hall, 1998.

[20] M. B. Holbrook, Consumer Value: a Framework for Analysis and Research, London; New York: Rout ledge, 1999.

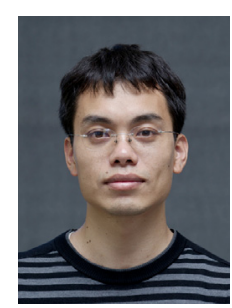

Xuqiang Pan was born in Wenzhou, China on November $1^{\text {st }}, 1978$. He obtained his bachelor's degree of Computer Science and technology from Zhejiang Normal University, China, 2000, his master's degree of ComputerScience from Hanzhou Dianzi University, China, 2006.

$\mathrm{He}$ is currently a lecture at the college of information and communications, Zhejiang Industry \& Trade Vocational College, China. His interest is in Ergonomics, Optimal Control, Computer Animation, and Image processing. He is a member of CCF.

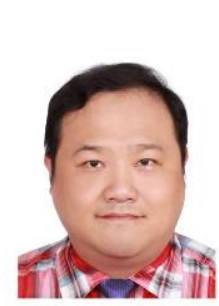

Yu-Ming Fei is the corresponding authorr. He is an associate professor of the College of Information and Communications of Zhejiang Industry \& Trade Vocational College, China. He received a Doctoral Degree from the Industrial and Systems Engineering, Chung Yuan Christian University, Taiwan.

His teaching and research interests include Ergonomics, Creativity Problem Solving, Enterprise Innovation and Human Computer Interface. 